Check for updates

Cite this: J. Mater. Chem. B, 2019, 7, 3100

Received 19th December 2018, Accepted 26th March 2019

DOI: $10.1039 / c 8 t b 03308 k$

rsc.li/materials-b

\section{Photo-crosslinkable recombinant collagen mimics for tissue engineering applications}

\author{
Liesbeth Tytgat, ${ }^{a b}$ Marica Markovic, $\dagger^{c}$ Taimoor H. Qazi, (D) ${ }^{d}$ Maxime Vagenende, ${ }^{a b}$ \\ Fabrice Bray, (D) José C. Martins, (D) ${ }^{f}$ Christian Rolando, (D) e Hugo Thienpont, ${ }^{a}$ \\ Heidi Ottevaere, (D) ${ }^{a}$ Aleksandr Ovsianikov, (D) $\uparrow^{c}$ Peter Dubruel ${ }^{b}{ }^{b}$ and \\ Sandra Van Vlierberghe (D) *ab
}

\begin{abstract}
Gelatin is frequently used in various biomedical applications. However, gelatin is generally extracted from an animal source, which can result in issues with reproducibility as well as pathogen transmittance. Therefore, we have investigated the potential of a recombinant peptide based on collagen I (RCPhC1) for tissue engineering applications and more specifically for adipose tissue regeneration. In the current paper, RCPhC1 was functionalized with photo-crosslinkable methacrylamide moieties to enable subsequent UV-induced crosslinking in the presence of a photo-initiator. The resulting biomaterial (RCPhC1-MA) was characterized by evaluating the crosslinking behaviour, the mechanical properties, the gel fraction, the swelling properties and the biocompatibility. The obtained results were compared with the data obtained for methacrylamide-modified gelatin (Gel-MA). The results indicated that the properties of RCPhC1-MA networks are comparable to those of animal-derived Gel-MA. RCPhC1-MA is thus an attractive synthetic alternative for animal-derived Gel-MA and is envisioned to be applicable for a wide range of tissue engineering purposes.
\end{abstract}

\section{Introduction}

Gelatin, a single-stranded protein extracted from collagen, is widely used for various biomedical applications due to its excellent biological characteristics and tunable physical properties upon chemical functionalization. ${ }^{1-4}$ To date, animal-derived gelatin has frequently been used to produce cell-interactive scaffolds for the regeneration of adipose tissue..$^{5-7}$ This type of tissue is often applied to restore volume loss in patients suffering from congenital defects, trauma or surgical deformities. ${ }^{8}$ However, there are increasing concerns associated with the use of materials

\footnotetext{
${ }^{a}$ Brussels Photonics (B-PHOT) - Department of Applied Physics and Photonics, Vrije Universiteit Brussel, Pleinlaan 2, 1050 Brussels, Belgium

${ }^{b}$ Polymer Chemistry \& Biomaterials Group - Centre of Macromolecular Chemistry (CMaC) - Department of Organic and Macromolecular Chemistry,

Ghent University, Krijgslaan 281, S4-Bis, 9000 Ghent, Belgium.

E-mail: sandra.vanvlierberghe@ugent.be

${ }^{c}$ Institute of Materials Science and Technology, TU Wien, Getreidemarkt 9, 1060 Vienna, Austria

${ }^{d}$ Julius Wolff Institute, Charité - Universitätsmedizin Berlin, Augustenburger Platz 1, 13353 Berlin, Germany

${ }^{e}$ Miniaturisation pour l'Analyse, la Synthèse et la Protéomique, USR 3290 Centre National de la Recherche Scientifique, University of Lille, Villeneuve d'Ascq, France

${ }^{f}$ NMR and Structure Analysis Unit - Department of Organic and Macromolecular Chemistry, Ghent University, Krijgslaan 281, S4-Bis, 9000 Ghent, Belgium

$\dagger$ These authors are associated with the Austrian Cluster for Tissue Regeneration (http://www.tissue-regeneration.at).
}

derived from animal sources for applications in modern healthcare. The drawbacks include problems with product reproducibility due to batch to batch variations and the risk of pathogen transmittance including prions. ${ }^{9,10}$ We hypothesize that a recombinant peptide based on human collagen type I could be an attractive alternative to animal-derived gelatin. RCPhC1 is produced by a yeast fermentation process and contains no animal-derived components. The peptide is highly reproducible and has a uniform molecular weight distribution of around $51 \mathrm{kDa}$. Furthermore, the peptide is enriched with cell-interactive arginine-glycine-aspartic acid (RGD) tripeptide sequences in its backbone, resulting in a good cell interaction. ${ }^{11,12}$ From literature, it is known that RCPhC1 is suitable for use in in vivo experiments. ${ }^{13}$

Gelatin and RCPhC1 dissolve under physiological conditions, which implies that both materials should be chemically crosslinked to avoid dissolution at body temperature. ${ }^{14,15}$ In the present work, the amine groups of RCPhC1 and gelatin were modified with photo-crosslinkable methacrylamide functionalities (RCPhC1-MA and Gel-MA, respectively) to avoid the use of potentially toxic crosslinkers such as glutaraldehyde and to reduce the long reaction times that are associated with 1-ethyl3-[3-dimethylaminopropyl]carbodiimide hydrochloride- $N$-hydroxysuccinimide (EDC-NHS) crosslinking (30 min versus $16 \mathrm{~h}$, respectively). ${ }^{16,17}$ Furthermore, the applied RCPhC1 contains 1.7 times more amine moieties that can be modified compared to the animal-derived gelatin. Subsequently, the modified 
materials were crosslinked into 2D hydrogel films upon UV-irradiation in the presence of a suitable photo-initiator. Lithium(2,4,6-trimethylbenzoyl)phenylphosphinate (Li-TPO-L or LAP) was applied in the experiments as a photo-initiator (PI) instead of the more often used PI Irgacure 2959 (I-2959). The latter PI has a molar extinction coefficient of $4 \mathrm{M}^{-1} \mathrm{~cm}^{-1}$ at $365 \mathrm{~nm}$, while Li-TPO-L has a molar extinction coefficient between 200 and $300 \mathrm{M}^{-1} \mathrm{~cm}^{-1}$ at $350-380 \mathrm{~nm}$, which results in a superior reactivity compared to I-2959. ${ }^{18-20}$ The developed hydrogels were physico-chemically characterized by gel fraction determination, swelling experiments and mechanical tests as well as in vitro biological assays and cell encapsulation experiments.

The aim of the present study was to investigate to what extent RCPhC1-MA effectively exhibits similar or superior characteristics compared to animal-derived Gel-MA. We hypothesized that RCPhC1-MA could be an attractive alternative to animalderived Gel-MA in terms of reproducibility, processing, mechanical strength, swelling properties and biocompatibility.

\section{Experimental section}

\subsection{Materials}

RCPhC1, commercially available as Cellnest ${ }^{\mathrm{TM}}$, was kindly provided by Fujifilm Manufacturing Europe B.V. Gelatin type B, isolated from bovine hides, was kindly supplied by Rousselot (Ghent, Belgium). Methacrylic anhydride and sodium hydroxide $(\mathrm{NaOH})$ were purchased from Sigma-Aldrich (Diegem, Belgium). Potassium phosphate monobasic $\left(\mathrm{KH}_{2} \mathrm{PO}_{4}\right)$ and sodium phosphate dibasic $\left(\mathrm{Na}_{2} \mathrm{HPO}_{4}\right)$ were obtained from Acros Organics (Geel, Belgium). All ${ }^{1} \mathrm{H}$-NMR spectra were recorded in deuterium oxide $\left(\mathrm{D}_{2} \mathrm{O}\right)$ purchased from Euriso-top (Saint-Aubin Cedex, France). The photo-initiator lithium(2,4,6-trimethylbenzoyl)phenylphosphinate (Li-TPO-L) was prepared according to the protocol reported by Markovic et al. ${ }^{20,21}$ Dialysis membranes, Spectra/ Por $^{\circledR}$ (molecular weight cut-off (MWCO) 12 000-14 $000 \mathrm{~g} \mathrm{~mol}^{-1}$ ), were obtained from Polylab (Antwerp, Belgium).

\subsection{Derivatization of RCPhC1 and gelatin}

The development of methacrylamide-modified RCPhC1 (RCPhC1-MA) and gelatin (Gel-MA) was performed according to the protocol for Gel-MA of Van Den Bulcke et al. ${ }^{14}$ Briefly, $10 \mathrm{w} / \mathrm{v} \%$ RCPhC1 (1 g, $0.65 \mathrm{mmol}$ amines) or gelatin (1 g, $0.39 \mathrm{mmol}$ amines) was dissolved in a $0.1 \mathrm{M}$ phosphate buffer $(\mathrm{pH} 7.8)$ at $40{ }^{\circ} \mathrm{C}$ (Table 1). Subsequently, 1 equivalent or 2.5 equivalents of methacrylic anhydride with respect to the number of amines of RCPhC1 and gelatin, respectively, was added dropwise to the solution followed by reaction for $1 \mathrm{~h}$ under continuous mechanical stirring. The excess of unreacted methacrylic anhydride and methacrylic acid formed during the reaction were removed via dialysis (MWCO 12 000-14 $000 \mathrm{~g} \mathrm{~mol}^{-1}$ ) against distilled water for $24 \mathrm{~h}$ at $40{ }^{\circ} \mathrm{C}$. Finally, the materials were isolated by freezing at $-20{ }^{\circ} \mathrm{C}$ and lyophilized (Christ freeze-dryer alpha I-5).
Table 1 The amino acid composition of RCPhC1 and gelatin

\begin{tabular}{lll}
\hline Amino acid & RCPhC1 $\left(\mathrm{mmol} \mathrm{g}^{-1}\right)$ & Gelatin $\left(\mathrm{mmol} \mathrm{g}^{-1}\right)$ \\
\hline Ala & 1.72 & 0.98 \\
Cys & 0.00 & 0.00 \\
Asp & 0.65 & 0.38 \\
Glu & 0.47 & 0.63 \\
Phe & 0.00 & 0.11 \\
Gly & 3.73 & 2.95 \\
His & 0.00 & 0.04 \\
Ile & 0.12 & 0.13 \\
Lys & 0.65 & 0.24 \\
Leu & 0.65 & 0.25 \\
Met & 0.18 & 0.06 \\
Asn & 0.00 & 0.00 \\
Pro & 1.95 & 1.25 \\
Gln & 0.23 & 0.00 \\
Arg & 0.65 & 0.39 \\
Ser & 0.00 & 0.26 \\
Thr & 0.00 & 0.18 \\
Val & 0.18 & 0.22 \\
Trp & 0.00 & 0.00 \\
Tyr & 0.00 & 0.01 \\
Ornithine & 0.00 & 0.07 \\
Hydroxylysine & 0.00 & 0.08 \\
& &
\end{tabular}

\subsection{Characterization of the hydrogel building block precursors}

2.3.1 NMR spectroscopy. ${ }^{1} \mathrm{H}$-NMR spectroscopy and ${ }^{1} \mathrm{H}-{ }^{13} \mathrm{C}$ heteronuclear single quantum coherence (HSQC) NMR spectroscopy (Bruker Avance II, $500 \mathrm{MHz}$ ) were used to confirm the modification of RCPhC1-MA and Gel-MA, and to determine the degree of substitution (DS). The samples were measured in $\mathrm{D}_{2} \mathrm{O}$ at $40{ }^{\circ} \mathrm{C}$.

2.3.2 Differential scanning calorimetry. The physical gelation behaviour of RCPhC1 and gelatin before and after modification was studied via differential scanning calorimetry (DSC). A TA Instruments Q 2000 with an RSC 500 cooler (Zellik, Belgium) was used for all measurements. The hydrogel precursor solutions $(10 \mathrm{w} / \mathrm{v} \%, 30 \mathrm{mg}$ dissolved in double distilled water) were injected into hermetic Tzero pans (TA Instruments, Zellik Belgium). An empty hermetic Tzero pan was used as a reference. A preparatory program was applied as described by Prado et al. ${ }^{22}$ First, the samples were heated at $20{ }^{\circ} \mathrm{C} \mathrm{min}^{-1}$ until a temperature of $60{ }^{\circ} \mathrm{C}$ was reached. After the samples were stabilized for 20 minutes, another ramp of $10{ }^{\circ} \mathrm{C} \mathrm{min}{ }^{-1}$ was set to cool the solutions to a temperature of $15{ }^{\circ} \mathrm{C}$. Then, the samples were stabilized for 20 minutes at $15{ }^{\circ} \mathrm{C}$. Subsequently, a temperature ramp of $20{ }^{\circ} \mathrm{C} \min ^{-1}$ was applied until $-10{ }^{\circ} \mathrm{C}$ was reached. Finally, the solutions were heated at $5.00{ }^{\circ} \mathrm{C} \min ^{-1}$ up to $60{ }^{\circ} \mathrm{C}$. The Q series software was applied for the analysis of the results.

2.3.3 Determination of the molecular weight of the gelatin and RCPhC1 derivatives. The molecular weight (MW) of the gelatin derivatives was determined via GPC measurements $\left(40{ }^{\circ} \mathrm{C}\right)$ on a Waters 610 fluid unit and a Waters 600 control unit equipped with a Waters 410 RI detector. The samples were dissolved in DMSO and the mobile phase consisted of $0.2 \mathrm{M} \mathrm{LiCl}$ dissolved in DMSO. The MW was determined using a calibration curve based on dextran standards (4440-401300 $\mathrm{g} \mathrm{mol}^{-1}$ ). Furthermore, the MW of RCPhC1 and RCPhC1-MA was determined 
using an Ab Sciex 4800+ proteomics matrix-assisted laser desorption/ ionization time-of-flight (MALDI-TOF/TOF) analyzer (SCIEX, Framingham, MA, USA). The measurements were performed in positive ion linear mode (2000 scans). The material was dissolved in water $\left(1 \mathrm{mg} \mathrm{mL}{ }^{-1}\right)$ and $1 \mu \mathrm{L}$ of each sample was spotted on the target plate and mixed with $1 \mu \mathrm{L}$ of matrix $\alpha$-cyano-4hydroxycinnamic acid (HCCA) $\left(10 \mathrm{mg} \mathrm{mL}^{-1}\right.$ water/acetonitrile (ACN) (30:70), 0.1\% formic acid).

\subsection{Preparation of hydrogel films via film casting}

The hydrogel films were prepared starting from 5 or $10 \mathrm{w} / \mathrm{v} \%$ RCPhC1-MA or Gel-MA solutions in double distilled water at $40{ }^{\circ} \mathrm{C}$. Next, $2 \mathrm{~mol} \% \mathrm{Li}$-TPO-L (relative to the amount of methacrylamide present) was added. Subsequently, the solutions were injected between two parallel glass plates covered with a Teflon release sheet and separated by a $1 \mathrm{~mm}$ thick silicone spacer. Chemically crosslinked hydrogel films were obtained by irradiating the plates from both sides with

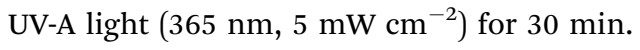

\subsection{Physico-chemical characterization of the hydrogels}

2.5.1 Rheology. A rheometer type Physica MCR-301 (Anton Paar, Sint-Martens-Latem, Belgium) with a parallel plate geometry (upper plate diameter of $14 \mathrm{~mm}$ ) was used to determine the mechanical properties of the hydrogels. The UV-induced chemical crosslinking of the hydrogels was monitored by injecting $300 \mu \mathrm{L}$ of each solution containing Li-TPO-L between the two plates (cfr. 2.4.1). A gap setting of $0.3 \mathrm{~mm}$ was applied. A strain of $0.1 \%$ and an oscillation frequency of $1 \mathrm{~Hz}$ were used as these values are within the linear viscoelastic range. Subsequently, the solutions were exposed for 400 seconds to UV-A irradiation at $37{ }^{\circ} \mathrm{C}$ (EXFO Novacure $2000 \mathrm{UV}$ light source at $365 \mathrm{~nm}$ with an intensity of $\left.3500 \mathrm{~mW} \mathrm{~cm}^{-2}\right)$ to determine the storage modulus $\left(G^{\prime}\right)$ of the hydrogels.

2.5.2 Determination of the gel fraction. The gel fraction was determined by weighing the dry mass $\left(m_{\mathrm{d}, 1}\right)$ of freeze-dried hydrogel films (6 $\mathrm{mm}$ diameter). Next, the samples were incubated in double distilled water for $24 \mathrm{~h}$ at $37{ }^{\circ} \mathrm{C}$. After reaching equilibrium swelling $(24 \mathrm{~h})$, the films were frozen and lyophilized to determine the dry mass $\left(m_{\mathrm{d}, 2}\right)$. The gel fraction can be derived using the following formula:

$$
\text { Gel fraction }(\%)=\frac{m_{\mathrm{d}, 2}}{m_{\mathrm{d}, 1}} \times 100
$$

2.5.3 Assessment of the crosslinking efficiency. The crosslinking efficiency was determined via high-resolution magic angle spinning (HR-MAS) ${ }^{1} \mathrm{H}-\mathrm{NMR}$ spectroscopy on a Bruker Avance II 700 spectrometer. The spectrometer contained a HR-MAS probe that was equipped with a ${ }^{1} \mathrm{H},{ }^{13} \mathrm{C},{ }^{119} \mathrm{Sn}$ and gradient channel. The spinning rate was set at $6 \mathrm{kHz}$. The freeze-dried samples were placed in a $4 \mathrm{~mm}$ zirconium oxide MAS rotor $(50 \mu \mathrm{L})$. Then, $30 \mu \mathrm{L}$ of $\mathrm{D}_{2} \mathrm{O}$ was added to let the samples swell. Finally, the samples were homogenized prior to the measurement. A Teflon ${ }^{\circledR}$ coated cap was used to close the rotor.

2.5.4 Determination of the swelling properties. The swelling properties of equilibrium swollen hydrogel films (6 mm diameter) were determined by submerging the samples in double distilled water for $24 \mathrm{~h}$ at $37{ }^{\circ} \mathrm{C}$. Subsequently, the excess of water was removed using tissue paper and the mass $\left(m_{\mathrm{s}}\right)$ of the hydrogel films was determined. Finally, the frozen and lyophilized films were weighed $\left(m_{\mathrm{d}}\right)$. The mass swelling ratio was calculated using the following formula:

$$
\text { Mass swelling ratio }(q)=\frac{m_{\mathrm{s}}}{m_{\mathrm{d}}}
$$

2.5.5 Statistical analysis. The statistical significance of the obtained results was evaluated via an $F$-test to determine whether or not the variances were different. Then, a Student $t$ test was performed to evaluate if two values were significantly different $(p<0.05)$ or not.

\subsection{In vitro biological evaluation}

2.6.1 Cell culture. The hTERT immortalized human adiposederived mesenchymal stem cell line ASC/TERT1 (Evercyte GmbH, Austria) was transfected with green fluorescent protein (GFP) to obtain permanently transfected green labelled cells following a previously established protocol. ${ }^{23}$ ASC-GFPs were cultured in EGM-2 medium (Lonza) supplemented with 10\% fetal bovine serum (Gibco). The cells were maintained in an incubator (high humidity, $5 \% \mathrm{CO}_{2}, 37{ }^{\circ} \mathrm{C}$ ) and the medium was changed every second day.

2.6.2 Functionalization of glass surfaces with methacrylate groups. Glass surfaces were functionalized with methacrylate groups to crosslink the material onto the glass plates. The glass bottom 8-well chambered $\mu$-slides (Ibidi GmbH, Germany) and the $18 \mathrm{~mm}$ cover glasses (Carl Roth) loaded in the appropriate staining rack were pre-treated in a plasma cleaner (PDC-002, Harrick Plasma, USA) for $10 \mathrm{~min}$. A solution consisting of deionized water $(50 \% \mathrm{v} / \mathrm{v})$, ethanol $(48 \% \mathrm{v} / \mathrm{v})$, glacial acetic acid $(0.3 \% \mathrm{v} / \mathrm{v})$ and 3-(trimethoxysilyl)propyl methacrylate $(2 \% \mathrm{v} / \mathrm{v})$ was stirred for $15 \mathrm{~min}$ and pipetted into the 8-well $\mu$-slides (approximately $0.3 \mathrm{~mL}$ per well). The glasses in the rack were soaked into the solution for $30 \mathrm{~min}$. After the surface treatment, the $\mu$-slides and cover glasses were rinsed twice with deionized water and dried in a drying chamber $\left(50{ }^{\circ} \mathrm{C}\right)$ for $1 \mathrm{~h}$. The $\mu$-slides and the glasses were irradiated with ultraviolet germicidal irradiation prior to each experiment.

2.6.3 Seeding of stem cells on hydrogel films. The behaviour and proliferation of ASCs on a surface covered with RCPhC1-MA or Gel-MA were evaluated in accordance with a protocol reported previously for Gel-MA-AEMA. ${ }^{24}$ In short, the material performance was benchmarked against the ASCs that were seeded onto tissue culture plastic (TCP). The RCPhC1-MA and Gel-MA surfaces were prepared by pipetting $30 \mu \mathrm{L}$ drops of a warm gel solution with a final composition of $10 \mathrm{w} / \mathrm{v} \%$ RCPhC1-MA or Gel-MA and $0.6 \mathrm{mM}$ Li-TPO-L in EGM-2 onto pre-warmed Teflon plates $\left(40{ }^{\circ} \mathrm{C}\right)$. The methacrylated cover glasses were carefully placed on top of the droplets and gently pushed against the Teflon plate resulting in glass substrates uniformly coated with RCPhC1-MA or Gel-MA. The Teflon plate with the coverslips was exposed to UV-light for 10 minutes (365 $\mathrm{nm}, 4 \mathrm{~mW} \mathrm{~cm}^{-2}$ ) to initiate polymer crosslinking. The obtained 
samples were then placed into 12-well culture plates pre-coated with agarose in order to avoid cell proliferation outside the intended sample area. A cell density of 50000 cells in $1 \mathrm{~mL}$ of EGM-2 was seeded per well and allowed to attach overnight. The following day, the first microscopy and metabolic activity assays were performed.

Primary human bone marrow derived cells (MSCs) were isolated and characterized as previously described. ${ }^{25}$ The cells were cultured at $37{ }^{\circ} \mathrm{C}$ in a $5 \% \mathrm{CO}_{2}$ atmosphere in low glucose Dulbecco's modified Eagle's medium (Sigma Aldrich, St. Louis, MO) supplemented with $10 \mathrm{v} / \mathrm{v} \%$ fetal calf serum (Biochrom AG, Berlin, Germany), $1 \mathrm{v} / \mathrm{v} \%$ penicillin/streptomycin (Biochrom), and $1 \mathrm{v} / \mathrm{v} \%$ GlutaMAX $^{\mathrm{TM}}$ (Thermo Fischer Scientific, Waltham, MA). The cells were passaged at $70-80 \%$ confluence and passages 3-4 were used for the experiments. To assess cell morphology, MSCs were seeded onto the hydrogel films (diameter: $8 \mathrm{~mm}$; height: $0.5 \mathrm{~mm}$ ) at a density of $5 \times 10^{4}$ cells per film using custom built PDMS molds (SYLGARD ${ }^{\circledR}$ 170). After overnight attachment, the hydrogel films were washed twice with PBS and transferred to well plates. At days 1, 3, and 7 after seeding, the cells were fixed with $4 \%$ formaldehyde, permeabilized with $0.1 \% \mathrm{w} / \mathrm{v}$ Saponin in $3 \%$ BSA-PBS for $10 \mathrm{~min}$ and incubated with Alexa Fluor $488^{\circledR}$ Phalloidin (Thermo Fischer Scientific) according to the manufacturer's instructions. The nuclei were visualized with DAPI. Images of the stained cells were acquired using an inverted fluorescence microscope (Leica). The cell spreading area was quantified using Fiji ImageJ software.

2.6.4 3D cell encapsulation. Aliquots of a suspension $(30 \mu \mathrm{L})$ with a final composition of 5 or $10 \mathrm{w} / \mathrm{v} \%$ RCPhC1-MA or Gel-MA in EGM-2, 0.3 or $0.6 \mathrm{mM} \mathrm{Li-TPO-L} \mathrm{for} 5$ and $10 \mathrm{w} / \mathrm{v} \%$ respectively and a cell density of 1 million ASC-GFP per $1 \mathrm{~mL}$ were drop casted onto methacrylated $\mu$-slides resulting in 30000 cells per droplet. Next, the slides were placed in the UV chamber in order to crosslink the gel, as previously described (see Section 2.6.3). The obtained hydrogels were soaked in EGM-2 and placed in the incubator. The samples were incubated for 7 days with microscopy and metabolic activity assays performed regularly.

2.6.5 Cell viability testing. The cell survival and proliferation on/in the material were evaluated using the PrestoBlue cell viability assay (Thermo Fisher Scientific) as well as laser confocal microscopy (LSM 700, Zeiss). PrestoBlue is a resazurinbased compound, which is modified by the reducing environment of a viable cell and turns into the highly fluorescent resorufin. In this manner, the fluorescent signal detected from the samples is proportional to the metabolic activity of the cells and is used to quantitatively measure cell viability and proliferation. According to the manufacturer's instructions, PrestoBlue was diluted in a 1:10 ratio with medium. In a 12-well plate with different surfaces, $500 \mu \mathrm{L}$ of the dilution was applied, and on the 3D structures in the $\mu$-slides, $300 \mu \mathrm{L}$ of the dilution was used per well followed by incubation for $2 \mathrm{~h}$ in a cell culture incubator. After incubation, $100 \mu \mathrm{L}$ of the dilutions was taken out in duplicate and put into a 96-well plate. The leftover PrestoBlue was aspirated and fresh medium was pipetted into the wells with cells. The fluorescence of the supernatants in the 96-well plate was measured using a plate reader (Synergy BioTek, excitation $560 \mathrm{~nm}$, emission $590 \mathrm{~nm}$ ). The measured fluorescence signals were corrected for background fluorescence. The cells used in this experiment were labelled with a green fluorescent protein to enable the observation of cell viability, proliferation and distribution on and within the material.

2.6.6 Statistical analysis. Statistical evaluation of data was performed using the software package SPSS Statistic (SPSS Inc., Chicago, IL) and Excel (Microsoft Office). The results are presented as an average of repeated measurements \pm standard deviation (SD). After having verified the normal distribution and homogeneity of the variance, a one-way ANOVA was carried out for comparison between the groups. If a significant difference was observed ( $p<0.05)$, post hoc multiple comparison tests were performed with Bonferroni correction to detect significant differences between the groups.

\section{Results and discussion}

\subsection{Methacrylation of RCPhC1 and gelatin}

RCPhC1 and gelatin were modified with methacrylic anhydride to introduce photo-crosslinkable functionalities along the backbone enabling subsequent UV-induced crosslinking in the presence of a suitable photo-initiator, Li-TPO-L (Fig. 1). The ${ }^{1} \mathrm{H}-{ }^{13} \mathrm{C}$ HSQC NMR the spectra only showed peaks at 5.8 and $5.6 \mathrm{ppm}$ in the ${ }^{1} \mathrm{H}$ NMR spectrum and at 120.9 and $120.8 \mathrm{ppm}$ in the ${ }^{13} \mathrm{C}$ NMR spectrum, which correspond to the vinyl protons of the methacrylamide functionalities. There are no signals at 5.8 and $6.2 \mathrm{ppm}$ and at $130.9 \mathrm{ppm}$ in the ${ }^{1} \mathrm{H}$ and ${ }^{13} \mathrm{C}$ spectra, respectively, which can be assigned to the vinyl protons of methacrylate functionalities, indicating that only the amine moieties are modified and not the hydroxyl groups. ${ }^{26}$ The degree of substitution (DS) of both materials was quantified via ${ }^{1} \mathrm{H}-\mathrm{NMR}$ spectroscopy by comparing the integration of the characteristic peaks of the vinyl protons of the methacrylamide functionalities at 5.5-6.0 ppm to the integration of the inert hydrogels of Val, Leu and Ile at 1.0 ppm (Fig. 2). During the modification of RCPhC1-MA, 1 equivalent of methacrylic anhydride was added with respect to the primary amines of the lysine moieties resulting in a DS of $90 \%$ (0.60 mmol methacrylamide per $\mathrm{g}$ RCPhC1). Furthermore, 2.5 equivalents of methacrylic anhydride were added with respect to the primary amines of lysine, hydroxylysine and ornithine for the modification of Gel-MA, which resulted in a DS of $97 \%(0.38 \mathrm{mmol}$ methacrylamide per $g$ gelatin). The latter result was in agreement with previous results obtained by Van Hoorick et al. ${ }^{15}$ Because RCPhC1

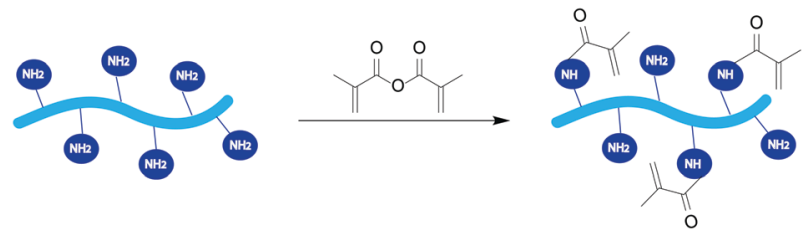

Fig. 1 Reaction scheme for the modification of RCPhC1 and gelatin with 1 or 2.5 equivalents of methacrylic anhydride, respectively, in a phosphate buffer $(\mathrm{pH} 7.8)$ at $40{ }^{\circ} \mathrm{C}$. 

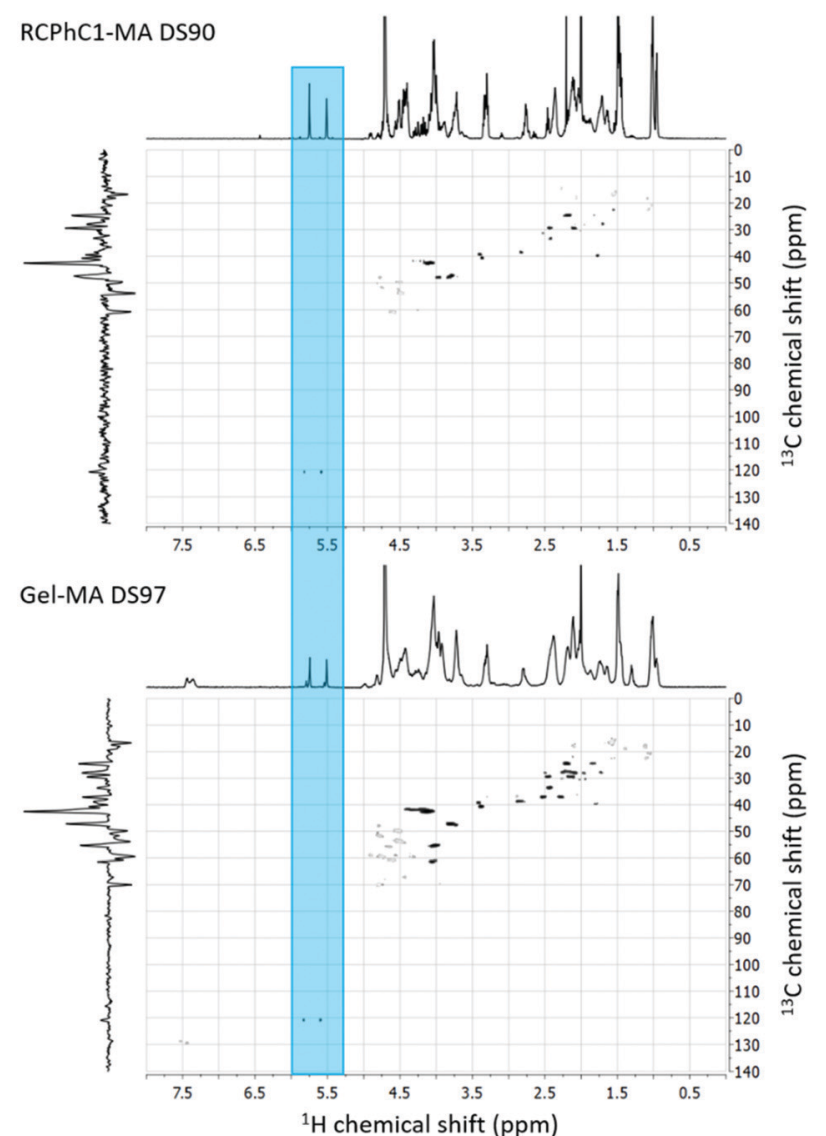

Fig. $2{ }^{1} \mathrm{H}-{ }^{13} \mathrm{C}-\mathrm{HSQC}$ 2D NMR spectra of RCPhC1-MA DS90 (upper panel) and Gel-MA DS97 (lower panel) in $\mathrm{D}_{2} \mathrm{O}$. The peaks corresponding to the vinyl protons of the methacrylate functionalities are highlighted.

has 1.7 times more amine groups per gram, the number of photocrosslinkable functionalities is also 1.6 times higher compared to Gel-MA.

\subsection{Assessment of the physical crosslinking behaviour of the hydrogel precursors}

Both gelatin and RCPhC1 exhibit an upper critical solution temperature (UCST), implying that below this temperature, the biopolymers form triple helices. Several factors influence the UCST including the hydrophilicity/hydrophobicity ratio, the molecular weight and the number of incorporated chemical functionalities. ${ }^{14}$ Visual observations indicated that RCPhC1-MA remained soluble at room temperature. This remarkable observation was further investigated by using differential scanning calorimetry (DSC). Fig. 3 shows that similar melting temperatures $\left(\sim 30{ }^{\circ} \mathrm{C}\right)$ were recorded for gelatin, Gel-MA and RCPhC1. The melting temperature for RCPhC1-MA is much lower, namely $\sim 17{ }^{\circ} \mathrm{C}$. Furthermore, the denaturation enthalpy associated with the different materials also differs (Fig. 3). From literature, it is known that the denaturation enthalpy is proportional to the number of hydrogen bonds present, which are responsible for triple helix formation. ${ }^{27}$ The incorporation of methacrylamide functionalities along the backbone of gelatin and RCPhC1 resulted in a $5 \%$ and a $14 \%$ decrease in hydrogen bonds, respectively.

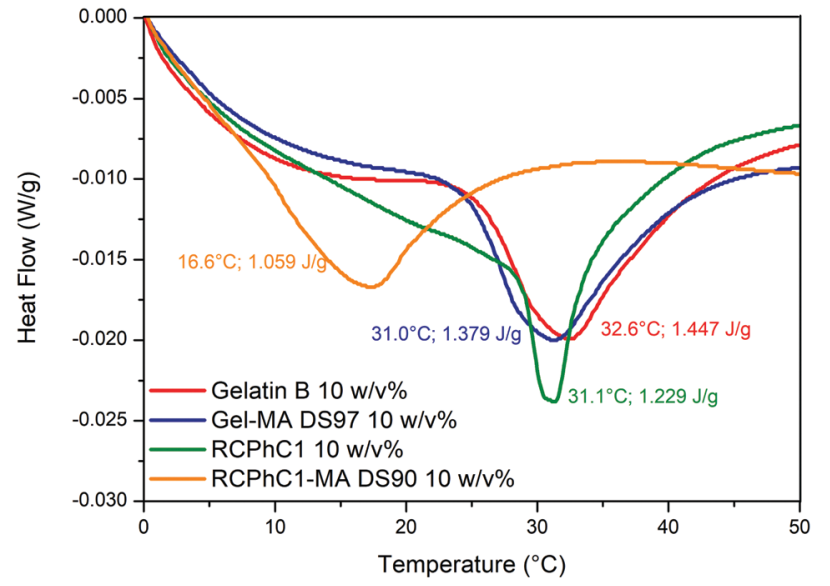

Fig. 3 DSC thermograms of aqueous gelatin, Gel-MA, RCPhC1 and RCPhC1-MA solutions.

We hypothesize that the higher amount of double bonds per chain and the lower molecular weight of RCPhC1-MA compared to Gel-MA (53 versus $91 \mathrm{kDa}$, respectively) have an impact on the reduced triple helix formation of RCPhC1-MA. The latter is due to the fact that a higher amount of photo-crosslinkable moieties and the lower molecular weight resulted in less entanglements between the RCPhC1-MA thereby hampering the triple helix formation. This observation is in accordance with previous results obtained for animal-derived gelatin by Van Hoorick et al., who investigated the physical crosslinking behaviour of different gelatin derivatives including Gel-MA and Gel-MA-AEMA. ${ }^{27}$

\subsection{Determination of the mechanical properties of the crosslinked hydrogels via rheology}

Rheology experiments were performed to determine whether or not the different number of photo-crosslinkable functionalities for RCPhC1-MA and Gel-MA has an influence on the final mechanical properties of the crosslinked hydrogels. In this respect, the storage modulus $G^{\prime}$ was monitored as this describes the elastic behavior of a material, which is related to the number of crosslinks present. It is known from literature

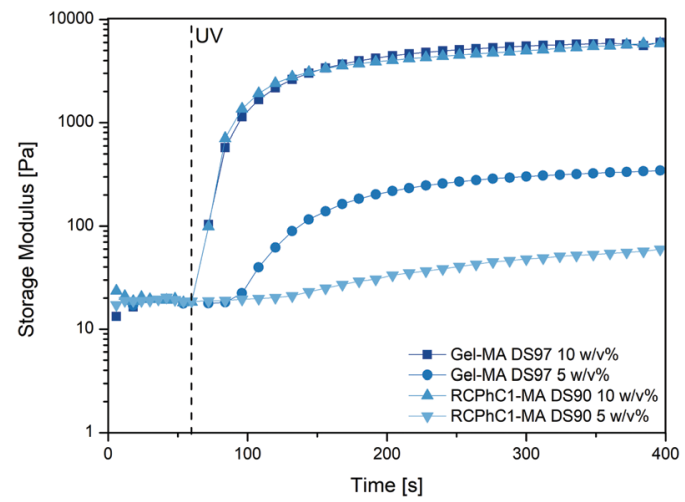

Fig. 4 Evolution of the storage modulus $G^{\prime}$ of RCPhC1-MA DS90 ( 5 and $10 \mathrm{w} / \mathrm{v} \%$ ) and Gel-MA DS97 ( 5 and $10 \mathrm{w} / \mathrm{v} \%$ ) as a function of time upon application of UV light at $37^{\circ} \mathrm{C}$. 
that $G^{\prime}$ becomes higher upon increasing the number of double bonds in the precursors, thereby resulting in a stronger network. ${ }^{28}$ As anticipated, a clear difference can be observed between the $5 \mathrm{w} / \mathrm{v} \%$ and $10 \mathrm{w} / \mathrm{v} \%$ hydrogels (e.g. a $G^{\prime}$ of $60 \mathrm{~Pa}$ for $5 \mathrm{w} / \mathrm{v} \%$ and $6000 \mathrm{~Pa}$ for $10 \mathrm{w} / \mathrm{v} \%$ RCPhC1-MA) (Fig. 4). Films formed starting from a higher biopolymer concentration exhibit a higher $G^{\prime}$ due to the increased number of photocrosslinkable moieties that can be chemically crosslinked upon UV irradiation. Furthermore, the results showed that the $G^{\prime}$ of RCPhC1-MA and Gel-MA is different for a concentration of $5 \mathrm{w} / \mathrm{v} \%$ (60 Pa versus $350 \mathrm{~Pa}$ respectively), while it is in the same range for $10 \mathrm{w} / \mathrm{v} \%(\sim 6000 \mathrm{~Pa})$ (Fig. 4). It can be anticipated that the photo-crosslinking of $5 \mathrm{w} / \mathrm{v} \%$ RCPhC1-MA is less efficient due to its lower molecular weight (53 kDa for RCPhC1-MA versus $91 \mathrm{kDa}$ for Gel-MA), resulting in less entanglements between the RCPhC1-MA chains. At higher polymer concentrations, the higher number of photo-crosslinkable functionalities of RCPhC1-MA can compensate for the lower amount of entanglements resulting in a comparable $G^{\prime}$ for both materials after crosslinking. This observation is in agreement with earlier reports described in the literature. Indeed, Gao et al. showed that materials with a lower molecular weight have fewer entanglements, resulting in lower mechanical strength. ${ }^{29}$

\subsection{Gel fraction and swelling experiments}

Similar gel fractions exceeding 90\% were obtained for both RCPhC1-MA- and Gel-MA-based hydrogels indicating successful hydrogel film formation (Fig. 5). No significant differences $(p<0.05)$ were observed for any of the developed hydrogel films. The results showed that for the $5 \mathrm{w} / \mathrm{v} \%$ as well as the $10 \mathrm{w} / \mathrm{v} \%$ concentration, stable hydrogels were formed. The obtained results are in accordance with previous data reported by Van Nieuwenhove et al. and Van Hoorick et al. ${ }^{27,30}$ The gel fraction results provided a first indication that the UV crosslinking was efficient. HR-MAS ${ }^{1} \mathrm{H}-\mathrm{NMR}$ spectroscopy experiments were performed to further substantiate the latter observation. This technique was used to gain insight into the double bond conversion by quantifying the number of double bonds that were consumed during UV-induced crosslinking according to the protocol of Van Vlierberghe et $a .^{31}$ A double bond conversion of around 95\% for RCPhC1-MA was determined, while it was around $70 \%$ for
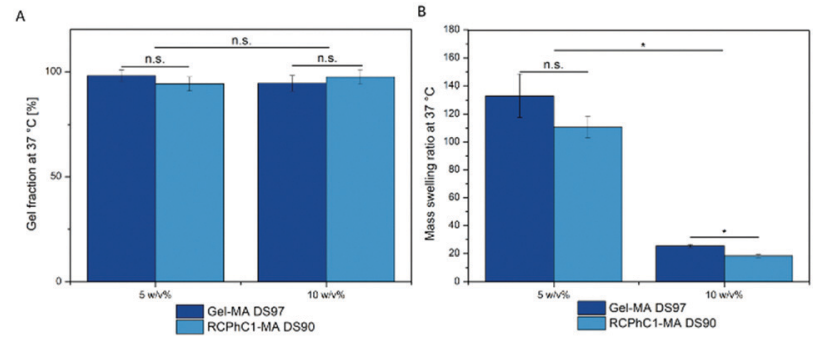

Fig. 5 (A) Gel fraction results of RCPhC1-MA and Gel-MA hydrogels (left panel). No results were significantly different $(p>0.05)$. (B) Mass swelling ratio of RCPhC1-MA and Gel-MA (right panel). n.s. is used to indicate that the pairs were not significantly different, while significant differences $(p<0.05)$ are indicated with an asterisk $\left(^{*}\right)$.
Gel-MA. The latter result was in agreement with the double bond conversion of $63 \%$ for Gel-MA-based hydrogels reported earlier by Van Nieuwenhove et al. ${ }^{30}$ We hypothesize that the lower molecular weight of RCPhC1-MA contributes to a higher mobility of the photo-initiator and the biopolymer resulting in a higher double bond conversion.

Hydrogels are ideal candidates for tissue engineering applications because they can closely mimic the aqueous environment of the extracellular matrix (ECM). Therefore, the mass swelling ratio is one of the important characteristics to determine whether or not a material is suitable to function as an ECM mimic. ${ }^{32}$ The results of the swelling experiments indicated that both hydrogels can absorb large amounts of water. The mass swelling ratio $q$ decreases from 111 to 18 for RCPhC1-MA and from 133 to 26 for Gel-MA depending on the biopolymer concentration (Fig. 5). As anticipated, the water uptake capacity of the hydrogel film decreases with increasing concentration because of the formation of a more densely crosslinked network due to the higher number of photocrosslinkable functionalities present. Interestingly, $10 \mathrm{w} / \mathrm{v} \%$ RCPhC1-MA swells significantly $(p<0.05)$ less compared to the same concentration of Gel-MA. We hypothesize that the latter is due to the fact that RCPhC1-MA has $24 \%$ less hydrophilic moieties such as aspartic acid and glutamic acid that attract water and contains $20 \%$ more hydrophobic functionalities (i.e. Ile, Leu, Val, Met and Phe) compared to Gel-MA (Table 1). The latter observation is in accordance with previous literature reports. Vázquez et al. reported that the water uptake capacity of a material decreases with increasing amounts of hydrophobic moieties present. ${ }^{33}$ In addition, from the literature, it is also known that the isoelectric point (IEP) can have an influence on the swelling behaviour of hydrogels. ${ }^{34}$ Gelatin B has an IEP of 5 , while RCPhC1 has an IEP of $10 .{ }^{32}$

\subsection{In vitro biological evaluation}

3.5.1 Evaluation of ASC-GFP survival after cell seeding. Animal-derived Gel-MA is considered as the gold standard in the tissue engineering field, as reflected by the numerous high impact papers published to date. ${ }^{35-38}$ For example, the results of Van Nieuwenhove et al. indicated that the cell viability of ASCs seeded onto hydrogel films based on Gel-MA DS95 exceeded $90 \%$, which was similar to the tissue culture plastic (TCP) control. ${ }^{39}$ In the present study, cell seeding experiments were performed using ASC-GFP to evaluate the biocompatibility of RCPhC1-MA and Gel-MA. A concentration of $10 \mathrm{w} / \mathrm{v} \%$ was used for these experiments, because of the limited stability of the $5 \mathrm{w} / \mathrm{v} \%$ hydrogels during handling. The obtained results indicated that the cell proliferation was slightly higher for the cells seeded on RCPhC1-MA compared to those on Gel-MA on days 1 and 2 (Fig. 6A), albeit not significant $(p>0.05)$. Furthermore, the cell proliferation of the cells cultured on TCP, RCPhC1-MA and Gel-MA was significantly higher on day 2 compared to day $1(p<0.05)$. Laser scanning microscopy (LSM) images showed that the cells nicely attached to the three different surfaces and preserved their spindle-like morphology (Fig. 6B). ${ }^{28}$ 


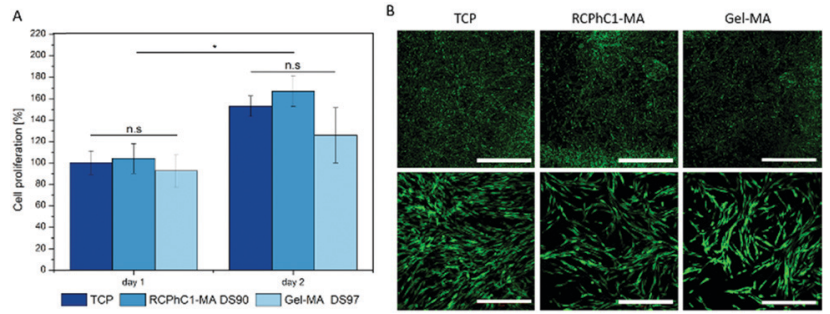

Fig. 6 (A) Evaluation of the metabolic activity of ASC-GFP seeded onto TCP, 10 w/v\% RCPhC1-MA and 10 w/v\% Gel-MA after 1 and 2 days. n.s. is used to indicate that the pairs were not significantly different, while significant differences $(p<0.05)$ are indicated with an asterisk (*). (B) Laser scanning microscopy images of ASC-GFP on both materials. The images were taken on day 1 with $2.5 \times$ (upper panel, scale bar $=2 \mathrm{~mm}$ ) and $10 \times$ (lower panel, scale bar $=500 \mu \mathrm{m}$ ) objectives.

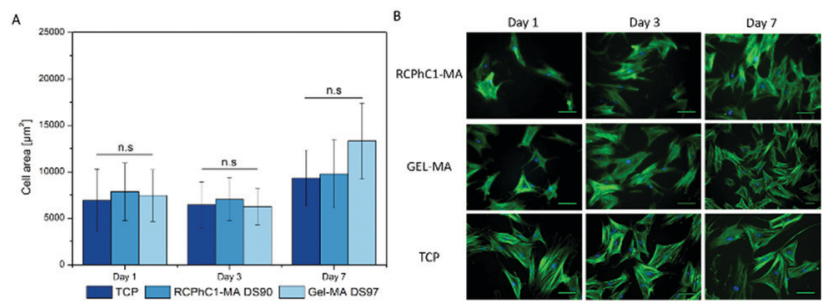

Fig. 7 (A) Evaluation of human MSCs seeded onto TCP, $10 \mathrm{w} / \mathrm{v} \%$ RCPhC1-MA and $10 \mathrm{w} / \mathrm{v} \%$ Gel-MA hydrogel films after 1, 3 and 7 days. n.s. is used to indicate that the pairs were not significantly different. (B) Laser scanning microscopy images of the seeded MSCs. The F-actin filaments and the nuclei of the cells were stained green and blue, respectively. The scale bar represents $100 \mu \mathrm{m}$.

The present study also focused on assessing the material versatility towards different stem cell types. Both adipose tissue and bone marrow derived stem cells have the ability to differentiate into the adipogenic lineage. ${ }^{39}$ Therefore, additional cell seeding experiments with bone marrow derived MSCs, seeded onto RCPhC1-MA and Gel-MA hydrogel films, were performed. The results indicated that the MSCs also nicely attached to RCPhC1-MA and Gel-MA due to the presence of the cellinteractive RGD tripeptides within the amino acid sequence. After day 1, the MSCs also started to proliferate and exhibited their spindle-like morphology (Fig. 7). The latter observation is in accordance with previous literature reports about culturing of MSCs on Gel-MA. ${ }^{40}$

3.5.2 Evaluation of ASC-GFP survival after cell encapsulation. Subsequently, the cells were encapsulated into Gel-MA and RCPhC1-MA hydrogels to evaluate whether or not the materials are able to support a 3D cell culture. The LSM images showed that the cells survived the encapsulation process, since they started to proliferate within the hydrogel (Fig. 8B). Furthermore, the results indicated that the metabolic activity of the cells encapsulated in a $10 \mathrm{w} / \mathrm{v} \%$ hydrogel was lower for both Gel-MA and RCPhC1-MA compared to the $5 \mathrm{w} / \mathrm{v} \%$ hydrogels on day 7 (Fig. 8A). These observations are in agreement with previous literature reports that indicated that high Gel-MA concentrations $(>7 \mathrm{w} / \mathrm{v} \%)$ forming denser crosslinked networks with higher stiffness resulted in a decreased cell proliferation and migration rate for the

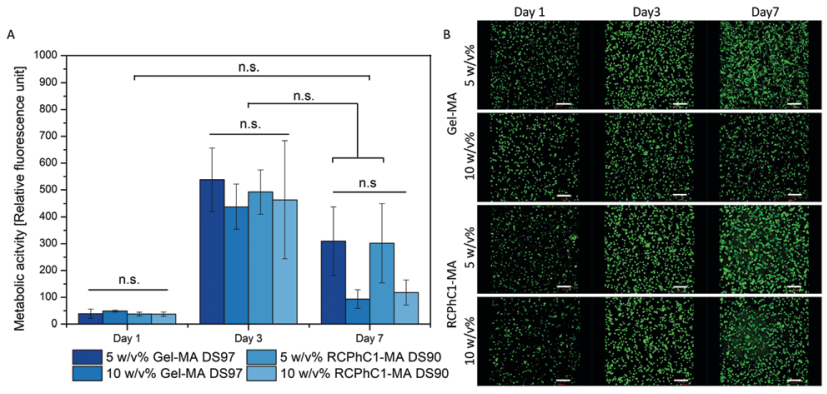

Fig. 8 (A) ASC-GFP was encapsulated in Gel-MA and RCPhC1-MA hydrogels ( 5 and $10 \mathrm{w} / \mathrm{v} \%$ ) and the metabolic activity of the cells was determined after 1,3 and 7 days. n.s. is used to indicate that the pairs were not significantly different. (B) Laser scanning microscopy images of the encapsulated ASC-GFP. The scale bars represent $200 \mu \mathrm{m}$

encapsulated cells. ${ }^{41,42}$ In addition, the experiments showed that there was no significant difference $(p>0.05)$ in the metabolic activity between the cells encapsulated in Gel-MA versus RCPhC1MA. Furthermore, the cells exhibited the same round cell morphology on days 1 and 3 in both hydrogels. On day 7, however, the ASC-GFP encapsulated in $5 \mathrm{w} / \mathrm{v} \%$ Gel-MA started to exhibit the spindle-like morphology to a higher extent compared to RCPhC1-MA (Fig. 8B). The obtained results are in agreement with previous literature reports covering the encapsulation of ASCs in Gel-MA. More specifically, Eke et al. showed that ASCs encapsulated in Gel-MA hydrogels demonstrated a cell viability of over $90 \%{ }^{36}$ It could be concluded that the in vitro biological characteristics of RCPhC1-MA are comparable to those of Gel-MA.

\section{Conclusions}

The present manuscript reported on the physical crosslinking behaviour of the hydrogel precursors as well as the mechanical properties, the gel fraction and the swelling properties of RCPhC-MA and Gel-MA. Furthermore, in vitro biological assays and cell encapsulation experiments were performed. The results showed that the physical crosslinking behaviour of the modified RCPhC1 is affected by the presence of the photocrosslinkable functionalities that affect the triple helix formation. The gel fraction together with the crosslinking efficiency results indicated that for both materials, the UV crosslinking was successful and that stable hydrogel films were formed. In addition, the mechanical properties of the final hydrogels are in the same range at a polymer concentration of $10 \mathrm{w} / \mathrm{v} \%$. However, the water uptake capacity of crosslinked RCPhC1-MA is lower than that for Gel-MA due to its lower hydrophilicity. In vitro biological evaluation indicated that RCPhC1-MA is biocompatible towards ASCs and MSCs. In addition, cell encapsulation experiments showed that the encapsulated ASCs survived the encapsulation process and started to proliferate within the hydrogel, which is an indication that RCPhC1-MA is an excellent ECM mimic with a comparable stem cell response to that of Gel-MA. It can be concluded that the properties of RCPhC1-MA are comparable with those of the gold standard Gel-MA after crosslinking. RCPhC1-MA is thus an attractive synthetic 
alternative to animal-derived Gel-MA for different biomedical applications including adipose tissue engineering.

\section{Conflicts of interest}

There are no conflicts to declare.

\section{Acknowledgements}

The authors would like to acknowledge Mr Tim Courtin for his assistance in recording the ${ }^{1} \mathrm{H}-\mathrm{NMR}$ spectra. The work of L. Tytgat was supported by the Research Foundation Flanders (FWO) under a PhD research fellowship (1S26616N). S. Van Vlierberghe would like to acknowledge FWO (Belgium) for financial support in the form of research grants (G005616N, G0F0516N, FWOKN273 and G044516N). A. Ovsianikov would like to acknowledge the financial support from the Austrian Science Funds (FWF Project No. I2444-N28). F. Bray and C. Rolando would like to acknowledge the IBiSA network for financial support of the USR 3290 (MSAP) proteomics facility.

\section{References}

1 T. Billiet, E. Gevaert, T. De Schryver, M. Cornelissen and P. Dubruel, Biomaterials, 2014, 35, 49-62.

2 J. Lewandowska-Łańcucka, K. Mystek, A. Mignon, S. Van Vlierberghe, A. Łatkiewicz and M. Nowakowska, Carbohydr. Polym., 2017, 157, 1714-1722.

3 L. J. Luo, J. Y. Lai, S. F. Chou, Y. J. Hsueh and D. H. K. Ma, Acta Biomater., 2017, 65, 123-136.

4 K. Yue, G. T. Santiago, A. Tamayol, N. Annabi, A. Khademhosseini, W. Hospital and S. Arabia, Biomaterials, 2016, 73, 254-271.

5 M. K. Phull, T. Eydmann, J. Roxburgh, J. R. Sharpe, D. J. Lawrence-Watt, G. Phillips and Y. Martin, J. Mater. Sci.: Mater. Med., 2013, 24, 461-467.

6 K. H. Chang, H. T. Liao and J. P. Chen, Acta Biomater., 2013, 9, 9012-9026.

7 B. W. Booth, C.-C. Yang and K. J. L. Burg, J. Biomater. Sci., Polym. Ed., 2012, 37-41.

8 C. J. Poon, M. V. Pereira, E. Cotta, S. Sinha, J. A. Palmer, A. A. Woods, W. A. Morrison and K. M. Abberton, Acta Biomater., 2013, 9, 5609-5620.

9 K. M. Pawelec and S. G. J. M. Kluijtmans, ACS Biomater. Sci. Eng., 2017, 3, 1100-1108.

10 D. Olsen, C. Yang, M. Bodo, R. Chang, S. Leigh, J. Baez, D. Carmichael, M. Perälä, E. R. Hämäläinen, M. Jarvinen and J. Polarek, Adv. Drug Delivery Rev., 2003, 55, 1547-1567.

11 A. J. García, Biomaterials, 2005, 26, 7525-7529.

12 M. Parvizi, J. A. Plantinga, C. A. F. M. Van SpeuwelGoossens, E. M. W. M. Van Dongen, S. G. J. M. Kluijtmans and M. C. Harmsen, J. Biomed. Mater. Res., Part A, 2016, 104, 503-516.

13 A. Tuin, S. G. Kluijtmans, J. B. Bouwstra, M. C. Harmsen and M. J. A. Van Luyn, Tissue Eng., Part A, 2010, 16, 1811-1821.
14 A. I. Van Den Bulcke, B. Bogdanov, N. De Rooze, E. H. Schacht, M. Cornelissen and H. Berghmans, Biomacromolecules, 2000, 1, 31-38.

15 J. Van Hoorick, H. Declercq, A. De Muynck, A. Houben, L. Van Hoorebeke, R. Cornelissen, J. Van Erps, H. Thienpont, P. Dubruel and S. Van Vlierberghe, J. Mater. Sci.: Mater. Med., 2015, 26, 247.

16 H.-W. Sung, R.-N. Huang, L. L. H. Huang and C.-C. Tsai, J. Biomater. Sci., Polym. Ed., 1999, 10, 63-78.

17 A. Sharma, S. Bhat, T. Vishnoi, V. Nayak and A. Kumar, BioMed Res. Int., 2013, 2013, 1-15.

18 S. Benedikt, J. Wang, M. Markovic, N. Moszner, K. Dietliker, A. Ovsianikov, H. Grützmacher and R. Liska, J. Polym. Sci., Part A: Polym. Chem., 2016, 54, 473-479.

19 B. D. Fairbanks, M. P. Schwartz, C. N. Bowman and K. S. Anseth, Biomaterials, 2009, 30, 6702-6707.

20 M. Markovic, J. Van Hoorick, K. Hölzl, M. Tromayer, P. Gruber, S. Nürnberger, P. Dubruel, S. Van Vlierberghe, R. Liska and A. Ovsianikov, J. Nanotechnol. Eng. Med., 2015, 6, 0210011.

21 M. Noe, R. Henne and A. Maase, Ger. Pat. Appl., WO2003068784A2, 2003.

22 J. R. Prado and S. Vyazovkin, Macromol. Chem. Phys., 2014, 215, 867-872.

23 L. Knezevic, M. Schaupper, S. Mühleder, K. Schimek, T. Hasenberg, U. Marx, E. Priglinger, H. Redl and W. Holnthoner, Front. Bioeng. Biotechnol., 2017, 5, 1-12.

24 D. Mandt, P. Gruber, M. Markovic, M. Tromayer, M. Rothbauer, S. Rudi, A. Kratz, S. F. Ali, J. Van Hoorick, W. Holnthoner, S. Mühleder, P. Dubruel, S. Van Vlierberghe, P. Ertl, R. Liska and A. Ovsianikov, Int. J. Bioprint., 2018, 4, 1-12.

25 G. Kasper, J. D. Glaeser, S. Geissler, A. Ode, J. Tuischer, G. Matziolis, C. Perka and G. N. Duda, Stem Cells, 2007, 25, 1985-1994.

26 C. Claaßen, M. H. Claaßen, V. Truffault, L. Sewald, G. E. M. Tovar, K. Borchers and A. Southan, Biomacromolecules, 2018, 19, 42-52.

27 J. Van Hoorick, P. Gruber, M. Markovic, M. Tromayer, J. Van Erps, H. Thienpont, R. Liska, A. Ovsianikov, P. Dubruel and S. Van Vlierberghe, Biomacromolecules, 2017, 18, 3260-3272.

28 G.-J. Graulus, A. Mignon, S. Van Vlierberghe, H. Declercq, K. Fehér, M. Cornelissen, J. C. Martins and P. Dubruel, Eur. Polym. J., 2015, 72, 494-506.

29 Y. Gao, L. Duan, S. Guan, G. Gao, Y. Cheng, X. Ren and Y. Wang, RSC Adv., 2017, 7, 44673-44679.

30 I. Van Nieuwenhove, A. Salamon, K. Peters, G. J. Graulus, J. C. Martins, D. Frankel, K. Kersemans, F. De Vos, S. Van Vlierberghe and P. Dubruel, Carbohydr. Polym., 2016, 152, 129-139.

31 S. Van Vlierberghe, B. Fritzinger, J. C. Martins and P. Dubruel, Appl. Spectrosc., 2010, 64, 1176-1180.

32 S. Van Van Vlierberghe, E. Schacht and P. Dubruel, Eur. Polym. J., 2011, 47, 1039-1047.

33 B. Vázquez, J. San Roman, C. Peniche and M. E. Cohen, Macromolecules, 1997, 30, 8440-8446.

34 C. Qiao, X. Cao and F. Wang, Polym. Polym. Compos., 2012, 20, 53-58. 
35 K. Yue, X. Li, K. Schrobback, A. Sheikhi, N. Annabi, J. Leijten, W. Zhang, Y. S. Zhang, D. W. Hutmacher, T. J. Klein and A. Khademhosseini, Biomaterials, 2017, 139, 163-171.

36 G. Eke, N. Mangir, N. Hasirci, S. MacNeil and V. Hasirci, Biomaterials, 2017, 129, 188-198.

37 J. W. Nichol, S. T. Koshy, H. Bae, C. M. Hwang, S. Yamanlar and A. Khademhosseini, Biomaterials, 2010, 31, 5536-5544.

38 K. Yue, G. Trujillo-De Santiago, M. Mois Es Alvarez, A. Tamayol, N. Annabi and A. Khademhosseini, Biomaterials, 2015, 73, 254-271.
39 I. Van Nieuwenhove, A. Salamon, S. Adam, P. Dubruel, S. Van Vlierberghe and K. Peters, Carbohydr. Polym., 2017, 161, 295-305.

40 R. Levato, W. R. Webb, I. A. Otto, A. Mensinga, Y. Zhang, M. van Rijen, R. van Weeren, I. M. Khan and J. Malda, Acta Biomater., 2017, 61, 41-53.

41 Y. Gu, L. Zhang, X. Du, Z. Fan, L. Wang, W. Sun, Y. Cheng, Y. Zhu and C. Chen, J. Biomater. Appl., 2018, 33, 609-618.

42 W. Liu, M. A. Heinrich, Y. Zhou, A. Akpek, N. Hu, X. Liu, X. Guan, Z. Zhong, X. Jin, A. Khademhosseini and Y. S. Zhang, Adv. Healthcare Mater., 2017, 6, 1-11. 